\title{
Discursive Construction of New Female Identity in Latest Hollywood Blockbuster Movies
}

\author{
Adnan Rashid Sheikh ${ }^{1}$, Faisal Rashid Sheikh ${ }^{2}$, Shaukat Khan ${ }^{1} \&$ Athar Rashid ${ }^{3}$ \\ ${ }^{1}$ English Language Institute, Umm Al Qura University, Makkah Mukarrama, Saudi Arabia \\ ${ }^{2}$ Department of English, Faculty of Language \& Literature, International Islamic University, Islamabad, \\ Pakistan \\ ${ }^{3}$ Department of Political Science and International Relations, Izmir University of Economics, Turkey \\ Correspondence: Adnan Rashid Sheikh, English Language Institute, Umm Al Qura University, Makkah \\ Mukarrama, Saudi Arabia. E-mail: numlnotes@gmail.com
}

Received: October 25, 2019

Accepted: November 27, 2019 Online Published: December 28, 2019

doi:10.5539/ijel.v10n1p265

URL: https://doi.org/10.5539/ijel.v10n1p265

\begin{abstract}
This study analyses the emergence of female portrayal in latest Hollywood superhero movies, after the \#MeToo global movement about awareness of sexual harassment. This research adopts a qualitative approach in analysing the constructs of doing and undoing gender in blockbuster movies by Marvel and DC comics. This study seeks to explore the shift towards discursive and screen empowerment of female lead and supporting characters. Such movies serve as a barometer of the cultural and social milieu and hence project how women can display range of capabilities, independence and emotional strength on screen, so to pave the way for viewers. The premise of this paper is rooted in events following $9 / 11$ and how blockbuster films helped in social uplifting by showing solutions till date. All such attempts of social restorations were led by all-male teams of superheroes, the events in recent couple of years are looking quite different. The discussion is rooted in transition from Zimmerman's idea of 'doing gender' (1997), for social conformity, to Deutsch's proposal of 'undoing gender' (2007), where females adopt a powerful position and voice. This approach resonates with latest, or fourth wave, of feminism. The emergence of able-minded stronger women is taking over and shaping new Man, a flexible, emotional and imperfect male. The paper also glimpses into other genres and studios' movies of the recent times to find signs of change.
\end{abstract}

Keywords: identity, superhero films, discourse, captain marvel, feminism

\section{Introduction}

Most movies are basically visual stories and construct social identities of national groups. According to some visual semioticians (e.g., Metz, 1974) they can be seen as having the same structural aspects of language (Dansei, 2018). It can be precisely stated that the filmic text enlarges language categories by blending scenes, sounds and said words in a subtle manner. It is for this sole reason that it should be regarded as a sign synthetically produced and comprising of both verbal and non-verbal depictions. This composition renders this medium strength and authenticity in capturing the imagination of audience across cultures. The interaction with filmic text, therefore, is a fusion of modalities of all human senses. According to Paik (2010) cinema is befitting for implementation of post-modern technique, which the directors of films utilize to achieve two goals, i.e., for depicting imagery to foster present-day cultural milieu, and for using language to work in close symmetry, for better meaning-making experience by the viewer (2010).

For a linguist, text of the film is the real substance, the starting point for considering all other elements. Language serves as the cement to all construction bricks of a film, i.e., both abstract bricks of themes and constructs, and concrete blocks of visible elements of sights and sound. Films serve as "a site on which various social groups, institutions, and ideologies struggle over the definition and construction of social reality" (Gurevitch \& Levi, 1985, p. 19). Consequently, films play an important role in framing. Zero Dark Thirty, about Osama Bin Laden, Body of Lies about Iraq war and American Sniper, to name a few, serve similar purposes. Their narratives have been somewhat perpetuated in the minds of the masses as to who was the hero and who was and will be villain (Note 1). 
The event of 9/11 provided an opportunity to Hollywood to capitalize on. Hollywood produced several war films about the attacks, thus amassing returns from cinematic representations of war, violence, fears of terrorism, attacks, battles, militarism and justified causes. In fact, films that depicted the US and its superheroes as a very imperialistic nation prepared to set the world straight, were appealing to US viewers as post-9/11 they were "wounded (and) vengeful" (Boggs \& Pollard, 2008, p. 566). Riegler (2014) explains that films released after 9/11 symbolize the "unbroken spirit, strove to reassert the symbolic coordinates of the prevailing American reality, and mobilized for a response to new challenge" (p. 104).

The emergence and boom of super-hero films is a direct consequence of the much-needed public sentiment of psychological uplift. Like super-hero comics during the two world wars, super-hero movies are used to reflect the realities around and provide suggestions and directions to the masses to believe in and feel comfortable about. The latter, however, proves to be a more subtle mode of coding deeper themes and messages, both political and non-political, inside an hour plus package of CGI-laden fantastic story of a super-hero (Note 2).

Besides many other direct and discrete messages, films happen to be the melting pot for the establishment and reinforcement of identities, i.e., political, gender, religious, etc. With each superhero film the gender roles, for example, are constantly in a state of flux. This paper intends to investigate the changing face of masculinity and/or the emergence of newer wave of on-screen feminism, in recent films of Marvel Cinematic Universe (henceforth MCU), like Captain America and Avengers film series, especially the films released in 2018-2019, in the backdrop of global \#MeToo movement against female sexual harassment. The latest and fourth wave of feminism marks the culmination of Feminist movement centering around previous issues such as reproductive rights, as well as new issues such as campus rape, workplace discrimination and sexual harassment. Moreover, the constant connectivity of the internet and dominance of \#MeToo movement, has created vibrant feminists in profusion who speak against gender discrimination and demand social change.

To put in a nutshell, the first wave of feminism centered around suffrage and legal gains, while the second moved to women's reproductive rights. The third wave introduced more complexity to the movement through gender equality and a focus on the individual battle women face. The fourth wave empowered the movement with internet and rectified the issues of campus rape, workplace discrimination etc. Hence the focus of this paper is discursive representation and construction of emerging female identity, while overshadowing constructs of common masculinity (Note 3).

On a broader level, MCU is replete with male characters who appear to be at the helm of affairs in their separate storylines. Captain America films, for instance, are all about a super soldier whose main strength is the physical and mental ability to endure hardships more than a normal human, a hyper masculine figure to be exact. His role remains consistent in his all appearances. Then there is another white male, but with a lot of riches and technical mind, Tony Stark. He evolves into Iron Man, whose main strength is his metallic smart AI suit, which makes him a militaristic masculine figure. Moving on, there is a god masculine figure, Thor, invincible god of thunder with unlimited power at his hand. The march of 'male saviours' continues and there is a half god, half man superhero Peter Quill from Missouri, in Guardian of The Galaxy. There is a biologically evolved green-bodied Hulk as well, aka Dr. Bruce Banner, who gets immensely big and devastating when angry, a superpower useful in fights. These characters seem to suggest different approaches, as well as options, to audience for tackling situations. Some of these suggest determinations, while others suggest using force.

Among the aforementioned troop of super heroes, the character of Captain America normally symbolizes a Manichaeistic view, the idea that the "forces of light and goodness are destined to confront evildoers," and jingoism too, which is the "ease in which a majority of Americans can be mobilized behind military venture" (Boggs \& Pollard, 2016, pp. 17-18). Moreover, Captain America is a "representative of national identity and one must not ignore the display of his physical body as a marker of his heroic manhood" (Barbour, 2015, p. 277). What Captain America represents as the national identity, is the conviction that "heroic manhood" is gained through hyper-masculinity. Captain America, who symbolizes the final wish-fulfilling fantasy will be weakling to superhero ever again - he is forever the superman of modern times, or at least of millennials. In the last couple of years, however, there has been a visible shift in representing super heroism in female form i.e., Captain Marvel. Being far more powerful (literally), and resolute she has received overwhelming response from female fandom. That is the main agenda of this paper to explore and discuss the phenomenon in direct comparison with an industry and society with built-in masculine undertones in almost all aspects, from writing to producing to acting to receiving awards.

\section{Research Objectives}

- To locate the discursive instances of new feminism in select latest Hollywood superhero films. 
- To find common thematic grounds, regarding newer gender roles that resonate across different films.

\section{Research Questions}

To uncover deeper meanings in such MCU superheroes movies, this paper aims at finding the patterns of dialogical decisions that lead towards built-up of hyper feminism as a direct reaction to masculinity in films. So, with this consideration the following are research questions for this paper.

- How do films project modern day feminism through discursive means, in post-9/11 milieu?

- How does MCU promote varying versions of masculinity, and emerging feminism, through their productions?

\section{Delimitation of the study}

In the years 2017-2019 there have been a number of films from major, big and small, production houses in Hollywood that have configured female characters in more powerful light. Hence this study focuses more on MCU's Captain Marvel, Avengers: Infinity Wars, Avengers: End Game, Antman and the Wasp and DC's Wonder Woman. Besides these main movies, there are mentions and quotes from Alita: The Battle Angel, X-Men: The Dark Phoenix etc. The volume of, and thematic similarity with, latest releases has been difficult for this paper to catch up with. So much so that there have been last minute additions of mentions of very latest films, and how they are strikingly treading the same line of newer feminism.

\section{Research Method}

Dialogues are what shape the characters and identities. Characters in all media are mouth pieces of writers, who keep up with the pulse of time, and looking glass of directors, who tap at the current of public sentiments and demands. The primacy of spoken word in a film is justified as it is coupled with a 'shown' dimension of camera angle, dress up and character positioning. It's the very dialogues that establish the mindset of masses as to how to articulate their opinion or judgment about certain class of people or idea. Now when the tide is flowing in favour of women, the female characters are given voice, dialogues on screen, to express that too.

The premise is based on West and Zimmerman's revolutionary concept of doing gender, in their ground-breaking research paper with the same title, in 1987, meaning gender is something we say and do, not something we are. It has been termed as one of the most significant and most cited writings in gender studies to date (Deutch, 2007). So, according to this construct gender is a socially established construct which defines what categorises as masculine and feminine. They have put forward the concept of gender being socially restricted due to 'normative conceptions' of men and women, which varies across cultures, ethnicities and times. This idea has been at the heart of contemporary gender studies both positively and negatively. Such construct is perpetuated due to accompanying language use. Although being very beneficial in outlining gender studies and initial constructs, their very definition and the very words 'doing gender' defeat the target of discouraging gender equality.

To this stance, Deutch (2007) believed that it means that "gendered institutions can be changed, and the social interactions that support them can be undone." He calls this renewed approach, undoing gender, the idea that gender specific roles can be undone or redone for better understanding. His main focus is on highlighting the social processes that can enforce resistance against traditional gender roles and comprehension. Deutch (2007) focuses more on the manner in which a flux in power dynamics is directly linked with undo gender. Being situated in the times of new and stronger wave of female empowerment, this discursive analysis grounds itself in Deutsch's (2007) undoing gender to analyse the different roles female superheroes play in latest films. Due to the recent awakening of female rights, undoing gender, is more evident than ever in films, media, advertising etc. (Note 4).

Hence this paper addresses how female protagonists do and undo gender, evoking resistance to stereotypical gender traits, behaviours, and roles. Their dialogues are analysed for establishing how being socially backed and empowered enables them to say, as well as do, things on screen. The relevance of such magnifies manifolds knowing the global impact factor, viewership and fan-following, these blockbuster films have. They can define how gender should be perceived in everyday life. Consequently, I have noted and presented the situations of these notable discursive points while analysing.

\section{Relevant Scholarship}

A film uses discursive acts to establish patterns to reinforce or create a message. Through discourses, actors constitute objects of knowledge, situations and social roles as well as identities and interpersonal relations between different social groups and those who interact with them (Fairclough, 2012). Furthermore, discursive 
acts are socially constitutive in a variety of ways (Fairclough, 2012). Firstly, they are largely responsible for the genesis, production and construction of social conditions. Secondly, they can contribute to the restoration, legitimation or relativisation of a social status quo (ante). Thirdly, discursive acts are employed to maintain and reproduce the status quo. Finally, discursive practice may be effective in transforming, dismantling or even destroying the status quo. On a social level, through linguistic representation in various dialogic contexts, such as films, discursive practices may influence the formation of groups and serve to establish or conceal relations of power and dominance between interactants, between social groups and classes, between men and women and between national, ethnic, religious, sexual, political, cultural and subcultural majorities and minorities (Danesi, 2002)

\subsection{Scale and Range of Blockbuster Films}

Blockbuster films are a specific form of discourse. According to Stuart Hall (1997), discourses are systems of representations which occur in forms of language, images and social practices. Consequently, discourses are processes through which meaning, and knowledge are produced (MacDonald, 2003). Within the film discourse, there are familiar symbols, images and meanings. According to Milestone and Meyer (2012), popular culture is a concept that "encompasses an enormous range of cultural texts and practices, from cinema films to newspaper articles, from designing computer games to playing music" (p. 22). The notion of 'popular' is controversial because it is vague, ambiguous, and can encompass many different meanings. I use the term 'popular culture' in the same way that Milestone and Meyer (2012) use it to refer to "a range of cultural texts which signify meaning through words, images or practices" (p. 22). Milestone and Meyer (2012) continue to explain that much of popular culture is media culture. Therefore, popular culture incorporates mass media, such as the press, film, and television.

Kevin Alexander Boon (2005) observed that as part of western popular culture (super) heroes can be watched as a 'metanarrative of masculinity'. Boon (2005) remarks that the hero figure provides benefits to a culture. For example, the hero can operate as an object of worship and an ideal, "in the sense that heroic qualities serve as models for privileged masculine behaviours" (p. 89). In his research, Miettinen (2011) examined how DC and Marvel superhero blockbuster films portrayed true heroes, such as police officers and firefighters, and collective trauma following the terrorist attacks of $9 / 11$. Boon (2005) expands on this stating that the terrorist attacks revitalized metanarratives in American popular culture. The heroic figure resurfaced due to the presence of a perceived threat, which warranted the revitalization and application of the heroic figure (Boon, 2005). Furthermore, Miettinen (2011) argues that post-9/11 DC and Marvel blockbuster films "did much more than just reflect the national trauma of $9 / 11 \ldots$ they took part in actively creating what would be seen in the popular media as the trauma of 9/11 and its solutions" (p. 61). Accordingly, DC and Marvel superhero blockbuster films offered an instantaneous response to the traumatic events through the use of iconic superheroes, such as Captain America, Spider-Man, and Wonder Woman, thereby creating an idealized American identity. Superhero blockbuster films, produced post-9/11, praised the true heroes of the terrorist attacks and there were rare cries for vengeance (Miettinen, 2011). Therefore, these films are characterized by a desire to understand the attacks and to re-establish collective security.

Hence, the superhero genres of blockbuster films have become a well-liked form of global popular culture, such as MCU's Avengers-Infinity War, Avengers Endgame, Captain Marvel, The Avengers, Iron Man, and Captain America., and DC's Superman-Man of Steel, Batman, Wonder Woman, Justice League, Aquaman etc. These films are based on their comics counterparts. Even being comics during the two World Wars, these titles have had social impacts, such as economic success and the recognition of an American art form and mythology, that is, the superhero (or superpower) that fights for truth and justice. With their film versions, the superhero narrative has been causing huge amount of industry data. The market research on film viewership in the U.S. is booming as the numbers are the milestones for society trends and barometer for what will sell more on screen. Using Facebook data, Brown (2016) found over 24 million film fans in the U.S. and of that population $46.67 \%$ are women. Schenker (2014) also found that female film characters were liked by 5.8 million people, of whom $62.07 \%$ were women. Additionally, Schenker (2014) observed that MCU wants to expand their female viewership by adding more female characters, because only $36.96 \%$ of their viewers are women. Ayyaz (2017) notes that females in DC Films make up 30.9\% of characters, while in Marvel Films they represent $30.6 \%$. He concludes that DC and Marvel Films are not representative of the U.S. population in which females make up 51\% of the population. This awareness is in direct consonance with domestic sales of blockbuster films which have been increasing over the years. According to Gus Lubin (2014), in 2000 film sales in the U.S. reached \$265 million, while in 2014 sales reached $\$ 870$ million and in 2018 it has crossed $\$ 1$ billion. 


\subsection{Marginalization and Revitalization of a Female Stance}

The superheroes ecosystem has brought in huge financial success and also has perpetuated socio-political messages. In establishing the social image of stability, masculinity or masculine approach towards hardships has been highlighted. It has been having direct reflection on the global cultural zeitgeist of gender discourse i.e., how gender is viewed and talked about in society. Gender is regarded as a social construct, by the feminist scholars of age, and its norms are evolved by society and people are assigned a gender that they must perform (Tong, 2014). To the society, people are characterized as "boy" or "girl", to possess certain behavioural features, that must match with two labels. The diversification of a boy/girl has been created by labelling of behavioural features, that is taken as the norm, and if this "rule" is not followed by any behaviour, is regarded as abnormal. Moreover, binary differences in language and discourse have limited the understanding of masculinity and femininity (Afzal, 2019). According to the rule under binary oppositions in language, masculinity is the opposite of femininity and vice versa. As such the categories for behavioural traits have been limited by the binary opposition to either masculine or feminine.

With this construction of characteristics of behaviour, the hegemonic masculinity is established and strengthened through superhero films after 9/11. Barrett (1996) describes hegemonic masculinity as a "particular idealized image of masculinity in relation to which images of femininity and other masculinities are marginalized and subordinated" (p. 130). Other groups, through hegemonic masculinity, are being less-than the ideal male figure. Moreover, the hegemonic masculinity also includes... "the process by which these groups and ideals form, the organizational situations and constraints that shape and construct these ideals and groups" (Barrett, 1996, p. 130).

Interestingly, in 2018-2019 there has been a visible shift towards female representation in production and on-screen presence. More and more females appear taking control of the tough situations in superhero category. The driving force of this trend stems from \#MeToo movement, about female sexual harassment in film industry, also awareness of financial inequality/wage gap faced by female actors and producers. Hence female directors, designers, actors and staff have garnered substantial coverage recently, establishing a global 'sisterhood' and pressurizing studios to offer more successful female content on screen. It appears that in recent times traditional macho masculinity is slowly morphing into a more accommodating man who can fail and require assistance of a powerful female. More and more films across studios and music icons are echoing with this newly found and much-awaited coverage of female powerfulness.

\subsection{The New Divided 'Man'}

Therefore, it must be marked how 'usual' masculinity is undergoing a drastic shift. The macho Captain America was shown a divided and somewhat dejected in the two last Avengers movies, Infinity War and End Game. This is important for this study to observe hegemonic masculinity that has paved way for or given in to a confident feminism in recent times and changed the discourse on female representation as a ripple effect of \#MeToo movement.

MCU, being a trans-media phenomenon, deserve scholarly deliberation and evaluation for its cultural and ideological outreach globally. For instance, with the current instalment of movies in MCU the characterization is becoming complex with every coming film. Most interestingly the gender portrayal has seen a tangible shift in last two instalments of MCU's bigger plot, Captain Marvel (2019) and Avengers: End Game (2019) The emergence of a female protagonist, saviour, is a trend breaking away from the most infatuated character of Captain America, the male, white super soldier capable of leading the world out of crisis. He has been at the helm of affairs for more than half a century of presence in comics and later in Avengers movies. The evolution of masculinity and its portrayal in movies is taking interesting turns wherein a more powerful and capable superhero joins the ranks, i.e., Captain Marvel. It is noteworthy that she has superpowers unlike Captain America who is biologically enhanced but remains a human and has weaknesses and emotions. His role in the first part of Avengers: Infinity War, appeared to be shaky and defeated in the face of a supernatural enemy with multiple powers, Thanos.

\section{Thematic Discursive Analysis and Critical Insights}

Below is a thematic analysis of the dialogues of iconic blockbuster movies featuring stronger and clearer image of powerful women. They appear to outwit and outdo their male counterparts by displaying range, ability, and brains to face and handle challenges. The usual role of being extraordinary used to be a white male thing. But there is a new chapter unfolding. The discursive development of these characters in their separate storylines is strikingly similar when compared. 


\section{1 'I've Got This'}

Below are a few instances wherein the female lead characters exhibit more range of sacrifice, confidence, compassion, and rigor, unlike the usual depictions of emotional and vulnerable beings. There is Natasha Romanoff, or Black widow, who has been part of MCU storylines, and her role has been of a wheel within the overall story. But this time she is finally given overdue coverage and is literally seated at the Avengers headquarters as in charge. Captain America, on the contrary, is displayed lost when planning next course of fight with Thanos, to bring all people back through his 'snap'. He is not sure if this plan works [as they are going to find Thanos].

Natasha Romanoff: This is going to work, Steve.

Steve Rogers: I know it is. Because I don't know what I'm going to do if it doesn't. (Russo, 2019)

Black Widow plays a catalytic role in the latest film too. It is she who assures Captain America and coordinates at Avengers headquarter after half of the avengers' team, along with human population vanished after Thanos' snap. Her role becomes a symbol of sacrifice, when she surpasses Hawkeye in sacrificing her life to gain 'soul stone'. Her exchange with Hawkeye, Or Clint Barton on the mountain expresses her true self and how she supersedes him in her approach towards the collective good of mankind. A message women keep getting out as they wish to be considered equals in real life too.

Clint Barton: I'm starting to think we mean different people here, Natasha.

Natasha Romanoff: For the last five years I've been trying to do one thing, get to right here. That's all it's been about. Bringing everybody back.

Clint Barton: Oh, don't you get all decent on me now.

Natasha Romanoff: What, you think I want to do it? I'm trying to save your life, you idiot.

Clint Barton: Yeah, well, I don't want you to, because I... Natasha, you know what I've done. You know what I've become.

Natasha Romanoff: Well, I don't judge people on their worst mistakes.

Clint Barton: Maybe you should.

Natasha Romanoff: You didn't (Russo, 2019).

In the same film, Captain Marvel is introduced to join the team as a sole saviour of the humanity. Her courage and confidence are quite unlike ever seen of a female superhero. Even in her initial scene in a room full of male avengers, she is mocked at by James Rhodes, the black accomplice of Iron Man. The exchange is quite significant in establishing how things are going to be for abled female characters. In this signature dialogue exchange in Avengers: End Game, Captain Marvel, comments on her indispensable role in the war against a mighty Thanos as

Bruce Banner: If we do this, how do we know it's going to end any differently than it did before?

Carol Danvers: Because before you didn't have me.

James Rhodes: Hey, new girl, everybody in this room is about that superhero life. And if you don't mind my asking, where the hell have you been all this time?

Carol Danvers: There are a lot of other planets in the universe, and unfortunately, they didn't have you guys (Russo, 2019).

The confidence Captain Marvel brings to the table resonates with the role of Wonder Woman, in Superman vs Batman and Justice League. It clearly appears that a shift towards powerful women in such male-ridden superhero universes is already in practice. In other words, when all else fails, a female saviour is what millennials want these days.

\subsection{Sisterhood and 'Daughterhood'}

The displays of females caring for each other and male being protective of female are quite iconic and meaningful in films between 2018-2019. To top all, Marvel showcases an overwhelming scene at the end of its 20-movies Avengers series, Avengers: The Endgame, which features a single shot display of powerful women in $\mathrm{MCU}$, both supporting and leading. An unusual and quite late realization but still a relief to see some gender representation with Scarlet Witch, Valkyrie, Okoye or Pepper Potts in her Iron (Wo)Man suit. The dialogue exchange between Captain Marvel and Peter Parker, the new Spiderman, sets the scene for the entry of female Avengers. 
Carol Danvers: Hey, Peter Parker. You got something for me?

Peter Parker: I don't know how you're going to get through all that.

Wanda Maximoff: Don't worry.

Okoye: She's got help.

[Pepper in her Iron Man suits appears, along with Mantis, Gamora, Valkyrie, Nebula, Hope and Shuri]

It is quite inspiring to see Marvel finally taking a position at the apex of screen time at the final stage of climax in a very expensive Avengers: Endgame. It appears as the studio's response to the wind of change about female representation on screen and establishing that Captain Marvel will lead the Avengers henceforth. In the same film, two sisters Nebula and Gamora reunite after being oppressed and used by cruel father.

Gamora: Tell me something. In the future, what happens to you and me?

Nebula: I tried to kill you... several times... but eventually, we become friends. We become sisters (Russo, 2019)

This reunion of sisters (dialogue) resonates with many other instances where women helped each other and teamed successfully, like Dr. Janet in Marvel's Antman and the Wasp, helps the suffering Ava by saying "Your pain... I can feel it. It hurts. It always hurts. I'm sorry. I think I can help you". Moreover, although racist but yet the reconnection and collaboration of Captain Marvel with her black side kick, Maria Rambeau is significant too. The interaction and partnership of these two empowers the very notion of sisterhood or best friends.

Maria Rambeau (reminding Carol Danvers (Captain Marvel) of her blurred past and relationship): You are Carol Danvers. You were the woman on that black box risking her life to do the right thing. My best friend. Who supported me as a mother and a pilot when no one else did. You were smart, and funny, and a huge pain in the ass. And you were the most powerful person I knew, way before you could shoot fire through your fists (Boden, 2019).

More attention to female characters is positioned in the shape of caring fathers for their daughter. Owing to the fact that sons do enjoy a privileged status, no sons were highlighted in any of these films. The father-daughter bond gets most of the screen and dialogue time. The relationship of Ant-man with his daughter is one such adorable relationship. He constantly is shown caring for her and playing along with her mischiefs and smart exchanges.

Cassie: So how long have you been Ant-Man again?

Scott Lang: Not long. It just sorts of happened. I'm sorry for lying to you, and I'm sorry for risking everything (Reed, 2018).

Antman being a good protective father challenges the villain in end sequence of Marvel's Antman by saying 'Why don't you pick on someone your own size?' Ironman is shown in the strikingly similar bond with his daughter in Avengers: End Game, who is smart and adorable and watches after his father's stuff. Her dialogue exchanges were perhaps the emotional milestones of the film, hence serving the purpose of catharsis in an action-packed tense film. Her dialogue, 'I love you 3000' is one of the most iconic dialogue to reinforce the on-screen father-daughter bond. Hawkeye appears teaching his daughter, not son, bow and arrow skill, in the opening shot of Avengers: Endgame. Also, when after her vanishing with Thanos snap, he uses quantum time travel and to go see his daughter (not son) back in time. Even after everything was fixed with Hulk's snap and all vanished came back to life, he rushed to go see his grown-up daughter (not son). There is a meaning to all of this A meaning towards an end. In Marvel's Antman and the Wasp, Dr. Hank is constantly assisted by his daughter, the Wasp, and the film sees instances of their reconciliation with each other and family reunion eventually. So, in a nutshell a lot of matter about Father-Daughter, Sister-Sister, Mother-Daughter are discursively established, giving audience reasons to love the films, hence drawing them in scores to cinema houses, which is good for business.

\subsection{Self Discovery}

The case of MCU's Captain Marvel has proved to be an important page in superhero universes so far. There is a common type of self-discovery in most of the female protagonists discussed in this paper, who's true 'potentials' have been locked up or hidden by some 'force', to keep them in check. Females are usually mocked for their emotional instability and their likelihood to break under pressure. This very construct has been combatted in most of the superhero movies specifically. Together with DC's Wonder Woman, there are two divergent kinds of feminist powerfulness put out there. Danvers or Captain Marvel is designed to be a character struggling with her fake past, that is not hers, and trying to break free from a male commander who keeps challenging her to use her 
head. Supreme Intelligence (SI) has restricted Captain Marvel's potential through a controller plugged into her neck and it keeps reminding her of the contribution of SI in giving her new life.

SI: Your life began the day it nearly ended. We found you with no memory. We made you one of us. So, you could live longer, stronger, superior. You were reborn (Boden, 2019).

She is kept under training with a male captain who keep pushing her to be better and better. While complaining about her inability to use her powers, she is instructed by her commander to master the skill of controlling

Carol Danvers: What is the point of giving me these if you don't want me to use them?

Yon-Rogg: I want you to use them. The Supreme Intelligence gave me responsibility of showing you how to use them.

Carol Danvers: I know how.

Yon-Rogg: Well if that were true, you could've knocked me down without them. Control your impulses.

[he points to her hands and then her head]

Yon-Rogg: Stop using this and start using this. I want you to be the best version of yourself (Boden, 2019).

Later in the movie, after a series of events when captivated by the bad guys (including her male colleague), she has realization of her true potential. In her meeting with SI during a sequence she breaks free from the neck-controller. Her signature dialogue sums up her newly found power and control

Carol Danvers (before unleashing her full powers): I've been fighting with one arm tied behind my back, but what happens when I'm finally set free? (Boden, 2019)

It is quite iconic and relatable in real world where mansplaining is usual. This conversation is a direct hit on the very idea how men keep instructing women to conduct themselves, hence restricting their potentials or using them. On the opposite side of spectrum is presented an Amazon warrior princess, Diana, in Wonder Woman who must just discover her true potential, without any men interfering. In an exchange between her mother and aunt about training and preparing for any possible encounter with Ares, the Greek war god, the wish to keep Diana away from truth is evident

Antiope: Ares is alive. You feel it as I do, in your bones. It is only a matter of time before he returns.

Hippolyta: The stronger she gets, the sooner he will find her.

Antiope: Hippolyta, I love her as you do. But this is the only way to truly protect her.

Hippolyta: You will train her harder than any Amazon before her. Five times harder, ten times harder, until she's better than even you. But she must never know the truth about what she is or how she came to be (Jenkins, 2017).

Wonder Woman, Diana is kept from knowing her 'true' self and potential. She was trained harder to be a combat and later she assists her lover in a World War, till she encounters Ares, the god of war, her mother always wanted to keep her away from. There is a symbolic element of Diana being told about God-Killer sword as a child, which she inwardly wishes to hold. But in her final encounter she learns a very different version when fighting Ares, who turns her God-Killer sword to ashes,

Diana (shocked): God Killer?

Ares: my dear child, it is not the god. killer (blows ashes of sword from his hands), you are (Jenkins, 2017).

This discovery brings a very different level of self-reliance and is quite symbolic to be shown on screen. She learns her capabilities and prowess yet chooses to show compassion towards evil scientist.

Diana: you are wrong about them. They are everything you say but so much more.

Ares: they do not deserve your affection

Diana: It's not about deserve but it's about what you believe (Jenkins, 2017).

So, her discovery leads to achieving a greater good. A message very consistent in all the self-discovering female heroes of recent times.

Prof. Charles in X-Men: Dark Phoenix (2019) taps Jean's hidden powers when she was a child so to help her forget the pain, she caused by killing her mother. It was a different kind of control, so to make her live a normal life and be unaware of the true range of power she has, which even surpasses his. There is a mixed message in the film. But this very notion of 'control by a man', is exploited by an alien female characters who instils doubt 
in Jean and encouraged her to see the larger picture. This exchange exhibits the full feminist message.

Jean Grey: I don't know who I am.

Vuk: Yes, you do. You're the girl who everyone abandons.

Jean Grey: Maybe they had good reason.

Vuk: Because of what's inside you? You're afraid of it because you think it makes you bad. Evil. All the words you've been taught to keep you in line. Words created a very long time ago by men with very little minds. They can't begin to comprehend what you are. Even your X-Men (Kinberg, 2019).

Towards the climax of film, a fully self-aware Jean makes a fatal choice between her life and of those she cherished to save. Women are displayed as emotionally weak, but Jean brings a different take to the construct in her final exchange with the villain who mocks her for her emotional instability.

Vuk: Your emotions make you weak.

Jean Grey: No, my emotions make me strong (Kinberg, 2019).

Hence, she plays the final role of sacrificing herself for the benefit of all other and disposes the solar flare in space, ending her life with it.

Another strand in the on-going discussion of self-discovering women leads to Alita in Alita- the Battle Angel narrates the story of a relic of combat robot who, when restored to her original state, has strength that proves off the charts for anything it encounters. Dr. Dyson who finds her robotic head from scrapyard rebuild her and names her after his late daughter. Another father-daughter narrative gets constructed as he cares for her and grows emotionally fond of her. As the story progresses Alita shows signs of combat which Vector tries to suppress. In later self-realization moments Alita expresses her true self to her benefactor;

Alita: This body, I feel a connection to it I can't explain. You know more about me than you're saying.

Dr. Dyson: I do, Alita, some things are better left forgotten.

Alita: Then I'll find out for myself (Rodriguez, 2019).

Hence proving that she was refrained from knowing who she really was and what was she capable of. She proves her metal in death race type battles. In her final sequence and exchange with the male architect of utopia in film, she challenges him

Alita: You made the biggest mistake of your life.

Vector: And what's that?

Alita: Underestimating who I am (Rodriguez, 2019).

It appears that women do need reminding and reminiscing of their capabilities, it seems. Also, the trailers of these very films ensure showing those glimpses of 'awakening' of female characters, as a means to convince female audience towards cinemas. These instances are not by chance but written, acted and shown to signal what kind of hurdles women face at the hand of 'forces' to keep them in control. There is a tangible amount of feminist underpinnings in all such instances, which befittingly serves as an apt analogy for the injurious consequences of the frequent gaslighting females usually are exposed to by socially protected men.

\section{Superhero Binaries}

In the recent times, the movies are showing the exact counterparts of the famous superhero categories. the superhero movies have all been about the categories instead of the superpowers of the individuals. For instance, Iron Man, being the tech genius, appears to be having a female counterpart in Black Panther. Shurri, the sister of Black Panther, appears to be a tech genius who is resourceful as well as smart and continuously inventing or trying new things. Similarly, we see another kind of captain that has absolutely no imperfections in her superpowers. Captain Marvel in the face of Captain America. We see a similar shift towards a female version of Superman in the Marvel's TV series called Superwoman. There are 2 upcoming movies which will present two stronger female figures in 2020. In Comic Con 2019 a movie about Lady Thor has been announced. It is unclear if she will also acquire godly qualities like the male Thor. Another movie that will showcase the replacement of the iconic Joker of Batman series, will be Margot Robbie's Birds of Prey (2020) who will also have an independent movie all by herself. From the trailer it appears that she will be accompanied by similar tough woman who will team up, like Batgirl, Hawkgirl, Vixen, Katana, Poison Ivy etc. The idea is situated in the latest comic edition of DC: Women of Action (October 22, 2019). It is interesting to note that such shifts and such bold decisions by the studio houses are based on contemporary realities. More and more women are making way into 
the male categories.

\section{The Changing Landscape of Media}

Despite the woes of female artists about monetary inequality, compared to male artists, the on-screen world is undergoing a visible change. Other than MCU, newer wave of feminism has also made way into studios like DC comics, Lionsgate, Bad Robot etc. Since gender construction is receiving over-whelming overhaul globally, DC comics converges on a similar mantra of female empowerment.

Collectively these industry giants are aiming at showcasing female heroes more than ever. Even other genres, like sci-fi Terminator series is catching up with a very masculine female saviour, Sarah O Conner, in the latest Terminator- The Dark Fate (2019), besides Arnold Schwarzenegger who has been the muscle man in last many instalments. Looks like she must return to make things right, despite being a mortal against invincible machines. Female coming to the assistance of male characters is now a thing. In latest Men in Black- International (2019) the addition of a female agent for the first time, Agent M, plays the real saviour role beside the dashing Agent H, who usually is the hero. This pattern is catching up in many genres and series of films, including animations.

The scores of recent powerful female characters do serve as a cathartic wish fulfilment of female audience. Atomic Blond, evil sister of Thor in Thor-Ragnarök (2017), the father-daughter bond, Jean in X-Men Dark Phoenix (2019), the latest instalment of X-men series, on-going TV series of Batwoman (2019-), and Supergirl (2015-) (opposed to Superman), in TV shows like Agent of Shield and individual characters of DC/Marvel universe. Also, Charlie's Angels (2019) remake is also around the corner after a much forceful and dominant female undertones in recent times. These characters are churning in a lot of revenue due to aggressive campaigning, press tours, product endorsements, and appearance on YouTube shows and podcasts.

A female evangelist, Lisbeth Salander of The Girl In The Spider's Web (2018), the "only hope" and warrior superhero Captain Marvel in Avengers: the End Game (2019), the goddesses of DC universe i.e., Wonder Woman (2017) of Amazon, Queen Atlantis of Sea, as well as Princess Komora, of Aquaman (2018), a dominant and more capable Wasp in Ant-man and the Wasp (2017), also mother of Ant-Man Dr. Janet van Dyne, who sacrificed herself to save millions and was lost in quantum realm, Alita the cyborg warrior of Alita: The Battle Angel, the female tech genius sister of Black Panther (2018) (aka Tony Stark of Wakanda), Shuri and very skilled combat guard Dora Milaje, to name a few, are emerging faces of feminist portrayals. The cyborg feminism, godly feminism, warrior queen feminism, genius feminism, female super soldier and battle angel, etc. are encouraging signs of powerful female representations in modern times.

\section{Conclusion}

This paper has attempted to capture the essence of change in female portrayal in biggest contemporary popular cinema, Hollywood, in recent times. It has investigated how the world is witnessing a new awakening of female characters on screen, with hopes to make difference in real life too. The studios like MCU and DC Comics have come forward in giving female characters more screen time, voice, position and capability to lead humanity out of problems, unlike recent long past, where all these privileges have been enjoyed by male protagonists. The discursive analysis of recurrent themes displays a visible shift in dialogue writing, resultantly handing authority to female characters. This game changing patterns of showing stronger mothers (than fathers), sisters, girlfriends itself points to the fact that modern audience yearns to have more of this. Knowing this hotspot of current times, writers and producers of popular films alike are contributing towards reflecting and cashing in on the changing landscape of modern feminism. The attempt, in this paper, has been made to witness this phenomenal on-screen change, right when it is happening and will have advanced much further when these words will be read.

\section{References}

Afzal, N. (2019). Discursive Strategies and Media Representation of Conflicts. International Journal of English Linguistics, 9(2), 1. https://doi.org/10.5539/ijel.v9n2p1

Ayyaz, S. (2017). An Interdiscursive Analysis of Post-the Innocence of Muslims Political Discourse at UN Forum. International Journal of English Linguistics, 7(6), 275. https://doi.org/10.5539/ijel.v7n6p275

Barbour, C. (2015). When Captain America Was an Indian: Heroic Masculinity, National Identity, and Appropriation. The Journal of Popular Culture, 48(2), 269-284. https://doi.org/10.1111/jpcu.12256

Barrett, C. (1996). The Imaginary Signifier (Trans. Ben Brewster, Celia Britton, Annwyl Williams, Alfred Guzzetti). Bloomington, IN: Indiana University Press.

Boden, A., \& Fleck, R. (Directors). (2019). Captain Marvel [Motion picture]. USA: Marvel.

Boggs, C., \& Pollard, G. (2017). The Hollywood War Machine: U.S. Militarism and Popular Culture. London, 
England: Routledge. https://doi.org/10.4324/9781315086279

Boon, K. A. (2005). Heroes, Metanarratives, and the Paradox of Masculinity in Contemporary Western Culture. The Journal of Men's Studies, 13, 301-312. https://doi.org/10.3149/jms.1303.301

Brown, J. A. (2016). The Superhero Film Parody and Hegemonic Masculinity. Quarterly Review of Film and Video, 33(2), 131-150. https://doi.org/10.1080/10509208.2015.1094361

Danesi, M. (2018). Understanding Media Semiotics. London, England: Bloomsbury Publishing.

Dargis, M. (2013). Bang, boom: Terrorism as a game. The New York Times. Retrieved from http://www.nytimes.com/2013/05/03/movies/iron-man-3-with-robert-downey-jr.html?_r=0\&pagewanted=p rint

Deutch. A. C. (2007). The Princess and The Magic Kingdom: Beyond Nostalgia, The Function of The Disney Princess. Women's Studies in Communication, 27, 34-59. https://doi.org/10.1080/07491409.2004.10162465

Fairclough, I., \& Fairclough, N. (2012). Political Discourse Analysis: A Method for Advanced Students. London, England: Routledge. https://doi.org/10.4324/9780203137888

Gurevitch, M., \& Levy, M. R. (1985). Mass Communication Review Yearbook. Thousand Oaks, CA: SAGE Publications.

Hall, S. (1997). Representation: Cultural Representations and Signifying Practices. Thousand Oaks, CA: SAGE.

Jenkins, P. (Director). (2017). Wonder Woman [Motion picture]. USA: DC/Warner Bros.

Kimmel, M. S. (2012). An Introduction to Critical Discourse Analysis in Education. Mahwah, New Jersey: Lawrence Erlbaum Associates.

Kinberg, S. (Director). (2019). X-Men: Dark Phoenix [Motion picture]. USA: Marvel Entertainment.

Lubin, G. (2014, August 26). The comic book industry is on fire, and it's about more than just the movies. Retrieved from http://www.businessinsider.com/the-comic-book-industry-is-on-fire-2014-8

Miettinen, M. (2011). Superhero Comics and the Popular Geopolitics of American Identity. Licentiate's Dissertation, School of Language, Translations and Literary Studies, University of Tampere.

Paik, P. Y. (2010). From Utopia to Apocalypse: Science Fiction and the Politics of Catastrophe. University of Minnesota Press. https://doi.org/10.5749/minnesota/9780816650781.001.0001

Reed, P. (Director). (2018). Ant-Man and the Wasp [Motion picture]. USA: Marvel Entertainment.

Riegler, T. (2014). "Mirroring Terror": The Impact Of 9/11 on Hollywood Cinema. Imaginations Journal of Cross-Cultural Image Studies, 5(2). https://doi.org/10.17742/image.tgvc.5-2.7

Rodriguez, R. (Director). (2019). Alita: Battle Angel [Motion picture]. USA: Twentieth Century Fox.

Russo, A., \& Russo, J. (Directors). (2018). Avengers: Infinity Wars [Motion picture]. USA: Marvel.

Russo, A., \& Russo, J. (Directors). (2019). Avengers: Endgame [Motion picture]. USA: Marvel.

Schenker, B. (2014, February 1). Facebook fandom spotlight: Who are the US comic fans? Retrieved from http://graphicpolicy.com/2014/02/01/facebook-fandom-spotlight-who-are-the-us-comicfans5/

Sherwood, S. (n.d.). How to Format Dialogue in APA. Retrieved from https://penandthepad.com/format-dialogue-apa-2033.html

Tong, R. (2010). James Cameron tells the astonishing story of Titanic, his breath-taking labour of love. Industry Central. Retrieved from http://www.industrycentral.net/director_interviews/JC01.HTM

Wayne, W. C., \& Don, H. Z. (2006). Doing Gender. Gender and Society, 1, 125-151. https://doi.org/10.1177/0891243287001002002

West, C., \& Zimmerman, D. H. (2009). Accounting for Doing Gender. Gender \& Society, 23(1), 112-122. https://doi.org/10.1177/0891243208326529

\section{Notes}

Note 1. Many irrelevant details have been trimmed from this chunk, to achieve focus.

Note 2. 9/11 linked with superhero films.

Note 3. Waves of feminism incorporated.

Note 4. Zimmerman discussed and incorporated. 


\section{Copyrights}

Copyright for this article is retained by the author, with first publication rights granted to the journal.

This is an open-access article distributed under the terms and conditions of the Creative Commons Attribution license (http://creativecommons.org/licenses/by/4.0/). 